1945-65 cohort then most of the women in the 1980-4 cohort will die from causes other than breast cancer.

We conclude that breast carcinomas diagnosed in the 1980s have a smaller primary tumour size, fewer axillary metastases, and more favourable histological features and are associated with better prognosis than cancers diagnosed a few decades ago. Improved survival with breast cancer can at least partially be explained by detection of increased numbers of small carcinomas with favourable histological characteristics.

This study was supported by the Cancer Society of Finland and Turku University Foundation. We thank the staff of the Finnish Cancer Registry for cooperation, and Juhani Tuominen of the department of biostatistics, Turku University, for help in statistical analyses.

1 Miller AB, Bulrook RD. UICC multidisciplinary project on breast cancer: the epidemiology, etiology and prevention of breast cancer. Int $\mathcal{f}$ Cancer 1986;37:173-7.

Ewertz M, Carstensen B. Trends in breast cancer incidence and mortality in Denmark, 1943-1982. Int f Cancer 1988;41:46-51.

3 Pollack ES, Horm JW. Trends in cancer incidence and mortality in the United States, 1969-76. F Natl Cancer Inst 1980:64:1091-103.
4 Adami H-O, Sparen P, Bergström R, Holmberg L, Krusemo UB, Ponten J. Increasing survival trend after cancer diagnosis in Sweden: 1960-1984. I Natl Cancer Inst 1989;81:1640-7.

5 Toikkanen S, Joensuu H. Prognostic factors and long-term survival in breas cancer. APMIS 1990;98:1005-14

6 Toikkanen S, Joensuu H, Klemi P. The prognostic significance of nuclear DNA content in invasive breast cancer: a study with long-term follow-up. Brf Cancer 1989;60:693-700.

7 UICC (International Union against Cancer). TNM classification of malignant tumours. 4th rev ed. Berlin: Springer Verlag, 1987.

8 World Health Organisation. Histological typing of breast tumours. International histological classification of tumours No 2. 2nd ed. Geneva: WHO, 1981

9 Hedley DW, Friedlander ML, Taylor IW, Rugg CA, Musgrove EA. Method for analysis of cellular DNA content of paraffin-embedded pathological material using flow cytometry. F Histochem Cytochem 1983;31:1333-5.

10 Fienberg SE. The analysis of cross-classified categorical data. Cambridge, Massachusetts: MIT Press, 1977.

11 Waterhouse J, Muir C, Correa P, Powell J. Cancer incidence in five continents. Vol 3. Lyon: International Agency for Research on Cancer, 1976: 510-1. (IARC Scientific Publication 15.)

12 Host $\mathrm{H}$, Brennhovd IO. The effect of postoperative radiotherapy in breas cancer. Int F Radiat Oncol Biol Phys 1977;2:1061-7.

13 Early Breast Cancer Trialists' Collaborative Group. Effects of adjuvan tamoxifen and of cytotoxic therapy on mortality in early breast cancer N Engl f Med 1988;319:1681-92.

14 Brincker H. Distant recurrence in breast cancer. Acta Oncol 1988;27:729-32.

15 Nielsen M, Thomsen JL, Primdahl S, Dyreborg U, Andersen JA. Breas cancer and atypia among young and middle-aged women: a study of 110 medicolegal autopsies. Br f Cancer 1987;56:814-9.

Accepted 14 April 1991
Human Diabetes and Metabolism Research Centre, University of Newcastle upon Tyne, Newcastle upon Tyne NE2 4HH

Y J Crow, medical student K G M M Alberti, FRCP, professor of medicine

J M Parkin, FRCP, late

professor of clinical paediatrics

Correspondence to: Mr Y J Crow, c/o Department of Medicine, The Medical School, University of Newcastle upon Tyne, Newcastle upon Tyne NE2 4HH.

BMF 1991;303:158-60

\title{
Insulin dependent diabetes in childhood and material deprivation in northern England, 1977-86
}

\author{
Y J Crow, K G M M Alberti, J M Parkin
}

\begin{abstract}
Objective-To determine the incidence of insulin dependent diabetes in the Northern region of England in children less than 16 years old in the period 1977 to 1986 and to relate the incidence data to an index of deprivation.
\end{abstract}

Design-Retrospective analysis of hospital case records identified from the regional health authority's computer; validation of the primary source with hospital clinic registers and community paediatric registers.

Setting-Northern region, excluding South Cumbria District Health Authority (659300 children under 16 in 1981).

Patients-All children diagnosed with insulin dependent diabetes before the age of 16 and resident in the region at time of diagnosis.

Main outcome measures-Incidence rates for the 10 year period and analysis of incidence rates within categories of deprivation.

Results -919 incident cases were identified. The validation procedure covered $54 \%$ of all cases identified and gave $\mathbf{9 5 \%}$ completeness of ascertainment. The average annual incidence over the 10 year period was $14 \cdot 8 / 100000$ for girls and $13 \cdot 4 / 100000$ for boys. The annual incidence for the most and least deprived areas of the region was $18.7 / 100000$ (95\% confidence interval $16 \cdot 2$ to $21 \cdot 5)$ for boys and $7 / 100000(5.6$ to 8.8$)$ for girls. There was a highly significant trend $(p<0.001)$ of decreasing incidence with decreasing level of deprivation.

Conclusions - In the north of England the incidence of childhood diabetes is related to material deprivation.

\section{Introduction}

Evidence for the role of environmental factors in the aetiology of insulin dependent diabetes ${ }^{1}$ has stimulated interest in epidemiological studies of the disease, and these have shown variations in incidence between countries and over time..$^{23}$ If environmental factors are of aetiological significance an analysis of incidence and a measure of socioeconomic category could be relevant. Previous studies have not found the incidence of diabetes to be significantly related to socioeconomic status $^{45}$ or social class, ${ }^{6}$ but these studies can be criticised because of the proxy used for social status. We analysed incidence data with respect to a composite index of material deprivation that has been shown to vary significantly with an index of health state in the Northern region.

\section{Patients and methods}

The Northern region covers a population of $3 \cdot 1$ million and is well contained with respect to medical services. Because of poor reporting rates South Cumbria District Health Authority was excluded from the present analysis.

Patients diagnosed with diabetes and treated with insulin before their 16th birthday and resident within the region at the time of diagnosis were eligible for inclusion. Patients in whom diabetes was associated with other disease states were excluded.

It was assumed that all individuals fulfilling the inclusion criteria would have been admitted to hospital at initial diagnosis of their disease. A regional health authority computer printout of all admissions with the code for diabetes mellitus (in the appropriate age group and time period) was used to identify all newly diagnosed diabetic patients. All case records were then checked to determine patients' eligibility for inclusion, and information was collected concerning date of birth, date of diagnosis, and address at time of diagnosis.

Validation of the primary data source was needed to test the assumption that all newly diagnosed diabetic patients were admitted to hospital and included on the printout. Questionnaires were sent to all consultant paediatricians in the region to determine their policy with respect to the admission to hospital of children 
newly diagnosed with diabetes. Two alternative sources of the names of patients with diabetes were used to validate the primary data source: clinic registers and community paediatric registers derived from school medical registers. Completeness of the primary source can be calculated as the proportion of patients identified through the validation process (all secondary data sources) who were also identified through the primary source, compared with all patients ascertained by the secondary sources. It has been recommended that the validation sources should ascertain at least $30-40 \%$ of all cases. ${ }^{8}$ Incidence rates were calculated using the 1981 census data and the registrar general's mid-year estimates of population and were standardised by age and sex using the direct method $^{10}$ with 1981 as the standard population. The $95 \%$ confidence intervals were calculated according to the Poisson distribution.

The deprivation index developed by Townsend $e t a l$ has been shown to be positively correlated with an overall health index in the Northern region. ${ }^{7}$ The score comprises the unweighted sum of four variablesunemployment, car ownership, home ownership, and overcrowding-to produce an overall deprivation index. Unemployment (the percentage of economically active residents aged 16 to 59 or 64 who are unemployed) relates to a general lack of material resources. Car ownership (the percentage of private households that do not possess a car) is a surrogate for current income. Home ownership (the percentage of private households not occupied by their owners) is a reflection of wealth as well as income. Overcrowding (the percentage of private households with more than one person per room) gives a general guide to living circumstances and housing conditions.

The smallest area for which population data (based on postcode) is now available is the enumeration district, which contains about 150 households. From the postcode given for each patient an enumeration district (that is, a geographical location) was derived, and the appropriate deprivation index score (the measure of material deprivation for that geographical unit) was attached. These scores were calculated for all enumeration districts in the region from the 1981 census data and ranged between -11 and +10 . The numbers of children by sex and by age were also known for each of these areas. Incidence rates were calculated for six equal groupings according to population aged less than 16 across the range of deprivation index scores. Rates were adjusted with respect to the age and sex structure of the total eligible population. Within each sixth the total number of children with diabetes was derived for the 10 year period, and these totals were divided by 10 to give the number of cases from which the rates were then calculated. The $95 \%$ confidence intervals were derived from the Poisson distribution, and $\chi^{2}$ test for trend was calculated according to the method of Armitage and Berry. ${ }^{12}$

Permission was obtained from all district ethical committees within the Northern region and from all consultant paediatricians. The study was approved by the Regional Paediatric Advisory Committee.

\section{Results}

The regional health authority's printout comprised a total of 1974 unique entries at 34 hospital sites, and 894 patients fulfilled the inclusion criteria (the printout did not differentiate between first and subsequent admissions). A total of 500 patients were identified through secondary sources, 25 of whom had not been identified with the printout, giving a total of $919(894+25)$ true incident cases. The primary data source was $95 \%$ complete $((500-25) / 500)$, and validation sources ascertained $54 \%(500 /(894+25))$ of the total number of cases identified.

The average incidence of diabetes was $14 \cdot 8 / 100000 /$ year $(95 \%$ confidence interval $13 \cdot 6$ to $16 \cdot 2)$ for boys and $13 \cdot 4(12 \cdot 1$ to $14 \cdot 8)$ for girls (table I). There were no significant trends with time. As expected, incidence increased with age: in boys the annual incidence was $9 \cdot 4 / 100000$ in the $0-4$ year age group, 14.9 at 5-9 years, and $18 \cdot 3$ for $10-15$ years, and in girls the corresponding figures were $8 \cdot 2,12 \cdot 4$, and $17 \cdot 3 / 100000$.

TABLE I-Annual standardised ${ }^{\star}$ incidence (cases/100000 population) of insulin dependent diabetes, Northern health region, 1977-86

\begin{tabular}{|c|c|c|c|c|}
\hline \multirow[b]{2}{*}{ Year } & \multicolumn{2}{|c|}{ Boys } & \multicolumn{2}{|c|}{ Girls } \\
\hline & No & Incidence & No & Incidence \\
\hline 1977 & 40 & $10 \cdot 9$ & 39 & $11 \cdot 1$ \\
\hline 1978 & 58 & $15 \cdot 9$ & 35 & $10 \cdot 0$ \\
\hline 1979 & 50 & $14 \cdot 1$ & 48 & $14 \cdot 1$ \\
\hline 1980 & 51 & $14 \cdot 7$ & 51 & $15 \cdot 4$ \\
\hline 1981 & 48 & $14 \cdot 2$ & 49 & $15 \cdot 2$ \\
\hline 1982 & 62 & $18 \cdot 8$ & 31 & $9 \cdot 9$ \\
\hline 1983 & 47 & $14 \cdot 7$ & 52 & $17 \cdot 0$ \\
\hline 1984 & 50 & $16 \cdot 1$ & 39 & $13 \cdot 1$ \\
\hline 1985 & 43 & $14 \cdot 2$ & 46 & $15 \cdot 6$ \\
\hline 1986 & 45 & $14 \cdot 8$ & 35 & $12 \cdot 3$ \\
\hline \multirow{2}{*}{$\begin{array}{l}\text { Total } \\
\text { Mean ( } 95 \% \text { confidence } \\
\text { interval) }\end{array}$} & \multicolumn{2}{|l|}{494} & \multicolumn{2}{|l|}{425} \\
\hline & \multicolumn{2}{|c|}{$14 \cdot 8(13 \cdot 6$ to $16 \cdot 2)$} & \multicolumn{2}{|c|}{$13 \cdot 4(12 \cdot 1$ to $14 \cdot 8)$} \\
\hline
\end{tabular}

*Standardised using the direct method within the age ranges $0-4,5-9$, and $10-15$ years for boys and girls.

Altogether 6629 enumeration districts were studied; they had a total population of 651953 children under 16. This total is less than the 659300 derived from the census data. Because data for some areas were not available because of the small size or military importance of the areas, we could not allocate 14 patients to enumeration districts, and of the 919 patients, $30 \mathrm{did}$ not have a postcode. Thus 875 patients were assigned an appropriate deprivation index score. Table II gives incidence rates for the six ranges of deprivation index score. The rates in the most and the least deprived areas of the region were $18 \cdot 7 / 100000(16 \cdot 2$ to $21 \cdot 5)$ and $7 / 100000(5 \cdot 6$ to $8 \cdot 8)$ respectively. The $\chi^{2}$ test for trend was highly significant $\left(\chi^{2}=41 \cdot 6, \mathrm{p}<0 \cdot 001\right)$.

TABLE II-Age and sex adjusted incidence of insulin dependent diabetes by categories of deprivation index

\begin{tabular}{|c|c|c|c|c|c|}
\hline \multirow[b]{2}{*}{ Category } & \multicolumn{2}{|c|}{ Population } & \multicolumn{2}{|c|}{ No of cases } & \multirow{2}{*}{$\begin{array}{c}\text { Incidence }(95 \% \\
\text { confidence } \\
\text { interval })\end{array}$} \\
\hline & Boys & Girls & Boys & Girls & \\
\hline 1 (most deprived) & 55807 & 53134 & 112 & 91 & $18.7(16.2$ to 21.5$)$ \\
\hline 2 & 55535 & 52863 & 72 & 57 & $11.9(9.9$ to 14.3$)$ \\
\hline 3 & 55734 & 53159 & 98 & 81 & $16 \cdot 5(14 \cdot 2$ to $19 \cdot 1)$ \\
\hline 4 & 55880 & 53014 & 72 & 86 & $14.5(12.4$ to $17 \cdot 0)$ \\
\hline 5 & 55367 & 53302 & 71 & 60 & $11.9(10.0$ to $14 \cdot 1)$ \\
\hline 6 (least deprived) & 55211 & 52947 & 43 & 32 & $7 \cdot 0(5.6$ to $8 \cdot 75)$ \\
\hline
\end{tabular}

\section{Discussion}

It is increasingly common for diabetic patients to start receiving insulin as outpatients,,$^{13}$ and the use of hospital admissions data for accurate assessment of the epidemiology of diabetes has consequently been questioned. ${ }^{14}$ By restricting age in the study to less than 16 years we hoped to minimise this problem. In response to a questionnaire, all consultant paediatricians dealing with diabetic children said, without exception, that they admitted newly diagnosed individuals to hospital. The exclusion of South Cumbria health district, the use of extensive validation procedures in areas bordering other regions (Carlisle, Berwick, and Middlesbrough), and the direct identification of the patient's address at time of diagnosis should have accounted for the cross boundary flow of diabetic subjects. The level of completeness and coverage of the validation procedure suggests that the study 
gives an accurate assessment of the epidemiology of insulin dependent diabetes in the Northern region in the age range and time period considered.

Social class is a concept intended to reflect the composite of socioeconomic factors to which individuals and groups are exposed, and factors that make up this composite are thought to have an important influence on welfare and health. The measure of social class employed should not be unnecessarily restricted to one aspect of social life - namely, the occupation of the head of household. The deprivation index used here is designed to reflect material deprivation and is a composite measure of factors that are central to material wellbeing. Previous studies have calculated incidence rates within social class categories according to one measure (family income) derived as an average over a large number of household units. ${ }^{45}$ Applying the deprivation index at the level of enumeration districts may be a theoretical improvement on an analysis using median family income or occupational status of the head of household.

This study related incidence data and materia deprivation at the level of the enumeration district. The matching of postcodes to enumeration district was by nearest grid reference, and $10-15 \%$ of addresses may be mismatched in this way, but as adjacent areas are likely to share similar characteristics the error of mismatching will be less than this. Care must be exercised when disaggregating data and attributing the characteristics of an area to individuals within that area. Individuals function within social aggregate situations, however-as Townsend et al showed, pockets of deprivation may exist within more affluent areas and exhibit relatively better measures of health outcome than might be expected, because of the area in which they function. ${ }^{7}$ We allocated addresses of individuals obtained over a 10 year period to enumeration district and gave them a deprivation index score according to data that had been derived from the census for one year only. The importance of this point depends on the change in the factors making up the score for that area over time. The use of 1981 for calculating the deprivation index and for the midpoint of the study helps to reduce this effect. The movement of families will limit the interpretation of data derived from the address at diagnosis in that no information was available on duration of residence. If families move between areas with similar social characteristics this consideration may not detract greatly from the conclusions. The importance of the duration of residence increases with increase in the length of the prediabetic phase because aetiologically important environmental agents may have exerted their effects months or years before diagnosis. The loss of data on 44 of the 919 of the patients is small but may be subject to some spatial bias as those from rural areas were excluded.

We found large differences in the risk of developing diabetes between deprived and affluent areas. The size of the difference in risk between groups indicates that the results may have real significance despite the problems that have been outlined above. It is, of course, not possible to determine what factors (for example, nutritional state, infection rates) are important in this relation, but these findings support the hypothesis that environmental agents play a part in the aetiology of the disease.

We are grateful for the help we received from the consultant paediatricians and medical records departments throughout the Northern region. We thank Ms K Denham of the information systems department of the Northern Regional Health Authority; Dr S Raybould of the Centre for Urban and Rural Development Studies, University of Newcastle upon Tyne; Dr P Phillips of the Health Care Research Unit, University of Newcastle upon Tyne.

1 Diabetes Epidemiology Research International Group. Preventing insulindependent diabetes mellitus: the environmental challenge. BMF 1987;295:

2 Diabetes Epidemiology Research International Group. Secular trends in incidence of childhood IDDM in 10 countries. Diabetes 1990;39:858-64.

3 Akerblom HK, Reunanen A. The epidemiology of insulin-dependent diabete mellitus (IDDM) in Finland and in northern Europe. Diabetes Car 1985;8(suppl 1): 10-6.

4 LaPorte RE, Orchard TJ. Kuller LH, et al. The Pittsburgh insulin-dependen diabetes mellitus registry: the relationship of insulin-dependent diabetes mellitus incidence to social class. Am $\mathcal{F}$ Epidemiol 1981;114:379-84.

5 Siemiatycki J, Colle E, Campbell S, Dewar R, Aubert D, Belmonte M. Incidence of IDDM in Montreal by ethnic group and by social class and comparisons with ethnic groups living elsewhere. Diabetes 1988:37: 1096-102.

6 Stewart-Brown S, Haslum M, Butler N. Evidence for increasing prevalence of diabetes mellitus in childhood. BMF 1983;286:1855-7.

7 Townsend P, Phillimore P, Beattie A. Health and deprivation: inequality and the north. London: Croom Helm, 1988

8 Diabetes Epidemiology Research International. Geographic patterns of childhood insulin-dependent diabetes mellitus. Diabetes 1988:37:1113-9.

9 Office of Population Censuses and Surveys. Census 1981. London: HMSO, 1981.

10 Bradford Hill A. A short textbook of medical statistics. 11th ed. Sevenoak Hodder and Stoughton, 1984:168-79.

11 Lilienfeld AM, Lilienfeld DE. Foundations of epidemiology. 2nd ed. Oxford: Oxford University Press, 1980:337.

12 Armitage P, Berry G. Statistical methods in medical research. 2nd ed. Oxford: Blackwell Scientific Publications, 1987:372-4.

13 Wilson RM, Clarke P, Barkes H, Heller SR, Tattersall RB. Starting insulin treatment as an outpatient: report of 100 consecutive patients followed for a year. FAMA 1986;256:877-80.

1+ Bingley PJ, Gale EAM. Incidence of insulin-dependent diabetes in England: study in the Oxford region, 1985-6. BMF 1989;298:558-60.

(Accepted 29 May 1991)

\section{ONE HUNDRED YEARS AGO}

By a curious coincidence the defective sanitary arrangements of the Chamber in which the French Deputies meet has been engaging the attention of a special committee at the same time that similar defects in the House of Commons have been occupying the leisure of a Parliamentary Committee in this country. The French Chamber seems, however, to be in a worse state than our own, for Professor Emile Trélat, who has written a special report on the subject for the Committee, expresses the opinion that the only way to remedy matters is to pull the present building down and erect another on an adjacent site. The Chamber, he says, is defective in every respect; it is, in particular, too small, Deputies are so crowded that they are bored (gênés) by their neighbours, have no place to keep their papers, are unable to communicate with each other, and cannot hear the speakers. The chamber, he says, "is unhealthy, for the occupants are condemned to breathe a foul atmosphere, and to endure too high a temperature." It is impossible to read M. Trélat's report, which is published in the Revue d'Hygiène, without perceiving that he believes that the work of the Chamber would be carried on with less heat, and with fewer of those "scenes" which now sometimes detract from its dignity, if the surroundings of the deputies were more healthy and more conducive to comfort of body and tranquility of mind. (British Medical fournal 1891;ii:329) 